\title{
Achieving high strength and low Young's modulus by controlling the beta stabilizers content in Ti-Nb-Ta-Zr-O alloys
}

\author{
D. Preisler ${ }^{1}$, J. Stráský ${ }^{1}$, M. Janovská ${ }^{2}$, H. Becker ${ }^{3}$, P. Harcuba $^{1}$, M. Janeček ${ }^{1}$ \\ ${ }^{1}$ Department of Physics of Materials, Charles University, Prague, Czech Republic \\ 2 Institute of Thermomechanics, Czech Academy of Sciences, Prague, Czech Republic \\ 3 Institute of Materials Science, Technische Universität Bergakademie Freiberg, Germany
}

\begin{abstract}
:
High strength and low Young's modulus is the desired combination of mechanical properties for the endoprostheses material. Metastable beta titanium alloys are promising materials for this application. In this study, four Ti-xNb-6Ta-7Zr-0.7O (wt.\%) alloys were prepared where $\mathrm{Nb}$ content ranged from 26 to $35 \mathrm{wt}$. \%. All alloys contained pure beta phase. The high oxygen content causes high microhardness $(330 \mathrm{HV})$, hence also the strength, while decreasing content of $\mathrm{Nb}$ leads to lower electrons per atom (e/a) ratio. The e/a ratio affects the Young's modulus which is highest (76 GPa) in Ti-35Nb-6Ta-7Zr-0.7O alloy with e/a=4.31 and the lowest $(64 \mathrm{GPa})$ in Ti-26Nb-6Ta-7Zr-0.7O with $\mathrm{e} / \mathrm{a}=4.24$. Such evolution of Young's modulus is in accordance with existing literature data, however, in comparison with other works, the Ti-26Nb-6Ta-7Zr-0.7O alloy shows double microhardness when compared to alloys with similar Young's modulus. Therefore, the approach of using controlled oxygen content for alloy design is very promising for development of biocompatible metastable beta Ti alloy for endoprostheses production.
\end{abstract}

\section{$\underline{\text { Introduction }}$}

Titanium and its alloys find their use in a variety of applications including aerospace industry, petrochemical industry and biomedicine. Apart from sufficiently high strength and corrosion resistance, requirements for the material in biomedical use have some specifics, namely use of biocompatible alloying elements and low Young's modulus. These specific requirements are met by the metastable $\beta$ Ti alloys, that possess pure $\beta$ phase (bcc structure) after quenching from the $\beta$ region. The biocompatibility requirement is fulfilled by using only proven biocompatible elements that are further able to stabilize the $\beta$ phase (Mo, $\mathrm{Nb}$, Ta, $\mathrm{Zr}$ ) [1].

Typically, $\beta$-Ti alloys have Young's modulus ranging between 50 - $100 \mathrm{GPa}$, depending of composition (elemental and phase composition) and processing [2-9]. These values of Young's modulus are higher compared to cortical bone (10 - 30 GPa) [10,11], but significantly lower than currently used materials such as $\alpha+\beta$ alloy Ti-6Al-4V (wt.\%) (110 GPa) or stainless steels (200 GPa). One of such $\beta$-Ti alloys Ti-35Nb-6Ta-7Zr (wt.\%), patented in USA 20 years ago, shows Young's modulus of 50 GPa [12]. The yield strength of this alloy is $450 \mathrm{MPa}$ which is not sufficient for the desired application as an endoprostheses material. The yield strength can be significantly enhanced by the addition of $0.7 \%$ of interstitial oxygen [13] (the initial "oxygen-free" alloy contained only $0.05 \%$ of oxygen). Resulting yield strength in the as-forged condition exceeds $1000 \mathrm{MPa}$, that is satisfactory for the desired application. Accordingly, the Vickers microhardness doubles as well from around $160 \mathrm{HV}$ for the low-oxygen content alloy to the value over $330 \mathrm{HV}$ in the alloy with $0.7 \mathrm{wt} \%$ of oxygen. However, the Young's modulus rises with the oxygen addition to $80 \mathrm{GPa}$, that is higher than in the initial alloy but still lower than the benchmark Ti-6Al-4V alloy.

According to Hao et al. [14], the minimum of Young's modulus occurs at specific value of number of electrons per atom (e/a ratio). In alloying systems in which stiff omega phase can be formed through diffusionless displacive transformation during cooling, this value is approx. 4.24 since for lower e/a ratio omega phase forms. In systems where the omega phase cannot form (for any reason), the optimal value of e/a is 4.15 . The e/a ratio of Ti-35Nb-6Ta-7Zr alloy with low oxygen content is 4.26 and this value rises to 4.31 after addition of $0.7 \%$ of oxygen. $\mathrm{Nb}$ content ( $\mathrm{Nb}$ has 5 valence electrons per atom) was decreased in the present study to decrease the e/a ratio and consequently to reduce Young's modulus without removing the strengthening effect of oxygen by the dislocation pinning and restraining them from motion [15].

\section{Materials and Methods}

Four alloys with various amount of $\mathrm{Nb}$ were prepared by electric arc melting of elemental metals in atmosphere of pure helium in company UJP Praha, Czech Republic. The castings were remelted 6 times in total to ensure homogenous composition and after first melting, $\mathrm{TiO}_{2}$ was added to achieve the desired content of oxygen $(0.7 \mathrm{wt} . \%)$. After casting, the content of oxygen, nitrogen and hydrogen was examined by carrier gas hot extraction method (CGHE). The nominal compositions of $\mathrm{Nb}$, Ta, $\mathrm{Zr}$ and measured compositions of $\mathrm{O}, \mathrm{N}, \mathrm{H}$ are shown in Table 1 together with the corresponding e/a ratio for each produced alloy.

Table 1: Nominal compositions (Nb, Ta, $\mathrm{Zr})$, measured compositions ( $\mathrm{O}, \mathrm{N}, \mathrm{H})$ and corresponding e/a ratio for four produced alloys.

\begin{tabular}{|c|c|c|c|c|c|c|c|c|}
\hline Alloy designation & $\begin{array}{c}\mathrm{Ti} \\
\text { (wt.\%) }\end{array}$ & $\begin{array}{c}\mathrm{Nb} \\
\text { (wt.\%) }\end{array}$ & $\begin{array}{c}\mathrm{Ta} \\
\text { (wt.\%) }\end{array}$ & $\begin{array}{c}\mathrm{Zr} \\
\text { (wt.\%) }\end{array}$ & $\begin{array}{c}\mathrm{O} \\
\text { (wt.\%) }\end{array}$ & $\begin{array}{c}\mathrm{N} \\
\text { (wt.\%) }\end{array}$ & $\begin{array}{c}\mathrm{H} \\
\text { (wt.\%) }\end{array}$ & $\begin{array}{c}\text { e/a } \\
\text { ratio }\end{array}$ \\
\hline $\begin{array}{c}\text { Ti-35Nb-6Ta-7Zr- } \\
\text { 0.7O }\end{array}$ & bal. & 35 & 6 & 7 & 0.67 & 0.04 & 0.02 & 4.31 \\
\hline Ti-32Nb-6Ta-7Zr- & bal. & 32 & 6 & 7 & 0.67 & 0.04 & 0.02 & 4.28
\end{tabular}




\begin{tabular}{|c|c|c|c|c|c|c|c|c|}
\cline { 2 - 9 } $0.7 \mathrm{O}$ & bal. & 29 & 6 & 7 & 0.70 & 0.03 & 0.02 & 4.26 \\
\hline $\begin{array}{c}\text { Ti-29Nb-6Ta-7Zr- } \\
0.7 \mathrm{O}\end{array}$ & bal. & 26 & 6 & 7 & 0.70 & 0.05 & 0.03 & 4.24 \\
\hline $\begin{array}{c}\text { Ti-26Nb-6Ta-7Zr- } \\
0.7 \mathrm{O}\end{array}$ &
\end{tabular}

After casting, the alloys were solution treated in Nabertherm vacuum tube furnace at $1000^{\circ} \mathrm{C}$ for 2 hours and water quenched. Two types of samples were prepared. Flat $2 \mathrm{~mm}$ thick samples for microstructural observations and microhardness measurements were cut by precision saw with diamond wafering blades, ground with SiC papers up to 2000 grit and polished on vibratory polisher Buehler Vibromet in successive steps on 3 polishing suspensions: Alumina $0.3 \mu \mathrm{m}$ for 8 hours, Alumina $0.05 \mu \mathrm{m}$ for 8 hours and Colloidal Silica $0.04 \mu \mathrm{m}$ for 4 hours. Second type of samples, for the Young's modulus measurements, were cut by precision saw into shape of bars with the dimensions $2 \times 3 \times 4 \mathrm{~mm}$ and carefully ground to achieve plane parallel bars.

Microstructural observations were conducted using scanning electron microscope (SEM) FEI Quanta 200F equipped with field emission gun, energy dispersive X-ray spectroscopy detector (EDS). Voltage of $10 \mathrm{kV}$ was used for microstructural observations by back-scattered electrons (BSE) and $20 \mathrm{kV}$ were used for EDS measurements. Microhardness was measured by Qness Q10 automatic indenter using Vickers method with load of $0.5 \mathrm{kgf}$ applied for $10 \mathrm{~s}$. At least 20 indents were measured to obtain a value and its error. Resonant ultrasound spectroscopy (RUS) was used to determine Young's modulus with both the excitation and signal collection by laser beam. Recorded eigenmodes were subsequently fitted by computer model to obtain the Young's modulus.

\section{$\underline{\text { Results and discussion }}$}

All produced alloys contain pure $\beta$ phase after solution treatment, therefore the $\beta$ transus temperature of each alloy lies below $1000^{\circ} \mathrm{C}$. The SEM micrographs are shown in Fig. 1 . All alloys contain very large $\beta$ grains with the size in the scale of $1 \mathrm{~mm}$. In some images, the grains are elongated in the direction of their growth during casting. The elongated grains in fact were present in all alloys, depending on the position of samples within the castings. No $\alpha$ phase was found in any produced alloy, even after close inspection of triple points of grain boundaries, where nucleation of the $\alpha$ phase occurs preferentially [16]. In addition, none of the alloys underwent the martensitic transformation $\beta->\alpha$ " which would manifest by plates going across the beta grains.
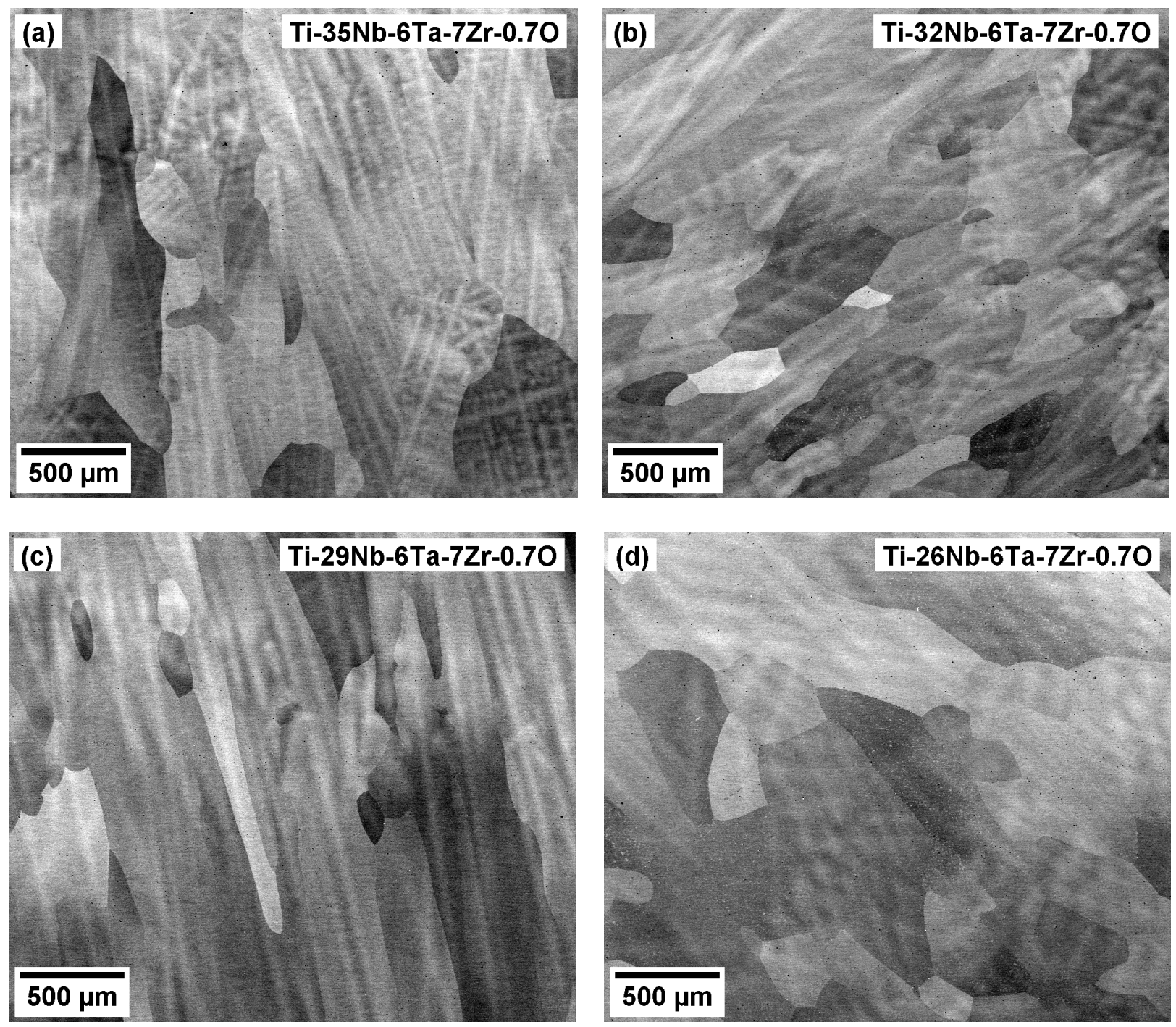
Fig. 1: BSE images of produced alloys: (a) Ti-35Nb-6Ta-7Zr-0.7O, (b) Ti-32Nb-6Ta-7Zr-0.7O, (c) Ti-29Nb-6Ta-7Zr-0.7O and (d) Ti-26Nb-6Ta-7Zr-0.7O.

All studied alloys, however, contain chemical heterogeneities caused by dendritic solidification of the melt. As shown in Fig. 2 (a), containing EDS line profile for $\mathrm{Ti}, \mathrm{Nb}, \mathrm{Zr}$ and $\mathrm{Ta}$ (oxygen could not be measured since its line is overlapped by L-line of Ti) in Ti$35 \mathrm{Nb}-6 \mathrm{Ta}-7 \mathrm{Zr}-0.7 \mathrm{O}$, the lighter areas are $\mathrm{Nb}$ and $\mathrm{Ta}$ enriched and these areas have a dendritic shape as these elements have high melting point compared to $\mathrm{Ti}$ and $\mathrm{Zr}$. The contrast in $\mathrm{BSE}$ is caused by higher atomic mass of $\mathrm{Nb}$ and $\mathrm{Ta}$ compared to $\mathrm{Ti}$.

In Fig. 2 (b), there is a BSE image of the edge of casting of the Ti-32Nb-6Ta-7Zr-0.7O alloy. As shown in this image, the part of the casting close to the surface is homogenous, contrary to the inside of the casting (more than approx. $3 \mathrm{~mm}$ in depth). Also, this surface region contains equiaxed grains, contrary to the elongated grains in the inhomogeneous part inside. The surface dendritefree region was found in all produced alloys and it originates probably due to fast cooling and solidification of the surface after turning the electric arc off. The surface dendrite-free area is therefore probably a chill zone and the rest of the casting is columnar zone in casting terminology.
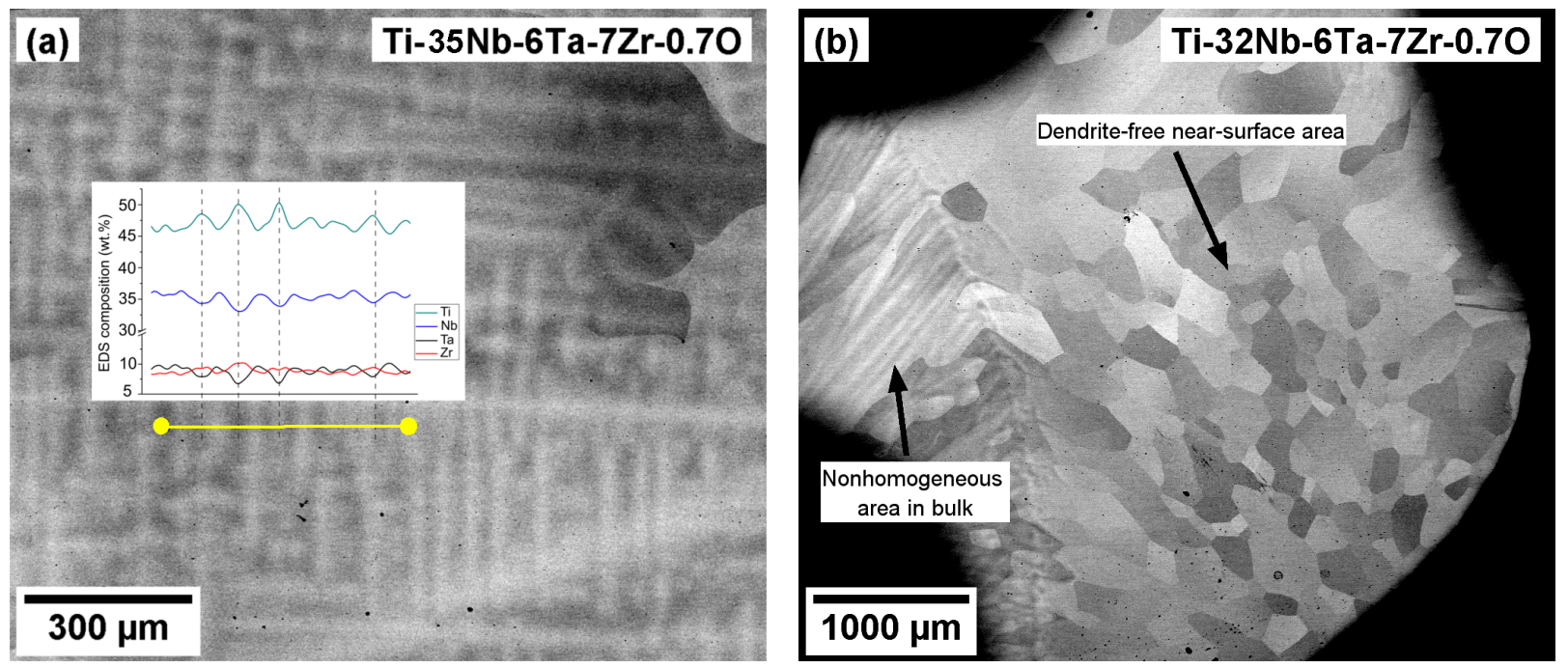

Fig. 2: (a) Dendrites in Ti-35Nb-6Ta-7Zr-0.7O and composition profile measured along the yellow line. Dashed lines correlate the maxima in Ti content with dark regions crossed by measured line. (b) Edge of Ti-32Nb-6Ta-7Zr- $0.7 \mathrm{O}$ casting containing approx. 3 $\mathrm{mm}$ thick area without dendrites.

Measured microhardness and Young's modulus for each alloy is shown in Table 2. The oxygen content and e/a ratio from table 1 are also repeated. All produced alloys retain the same microhardness value, given the statistical errors. The small variations in oxygen content (in scale of hundredths of percent) do not have a significant effect on microhardness. On the other hand, the Young's modulus decreases with decreasing e/a ratio of each alloy, as proposed in the Introduction. The highest value of $76 \mathrm{GPa}$ is obtained in the alloy with original composition Ti-35Nb-6Ta-7Zr-0.7O and this value is comparable to previously obtained one (80 GPa [13]). The lowest value of Young's modulus, $64 \mathrm{GPa}$ was achieved in the alloy Ti-26Nb-6Ta-7Zr-0.7O having e/a ratio 4.24.

Table 1: Microhardness and Young's modulus of produced alloys.

\begin{tabular}{|c|c|c|c|c|}
\hline Alloy designation & O (wt.\%) & $\begin{array}{c}\text { Microhardness } \\
(\mathrm{HV})\end{array}$ & $\begin{array}{c}\text { e/a } \\
\text { ratio }\end{array}$ & $\begin{array}{c}\text { Young's } \\
\text { modulus (GPa) }\end{array}$ \\
\hline Ti-35Nb-6Ta-7Zr-0.7O & 0.67 & $333 \pm 5$ & 4.31 & 76 \\
\hline Ti-32Nb-6Ta-7Zr-0.7O & 0.67 & $328 \pm 5$ & 4.28 & 72 \\
\hline Ti-29Nb-6Ta-7Zr-0.7O & 0.70 & $328 \pm 5$ & 4.26 & 66 \\
\hline Ti-26Nb-6Ta-7Zr-0.7O & 0.70 & $333 \pm 5$ & 4.24 & 64 \\
\hline
\end{tabular}

To compare the obtained results to those of other authors for different developed alloys with various composition, values of Young's modulus and microhardness were plotted against each other in Fig. 3. Following previous studies were used: Stráský et al. [13], Furuta et al. [3], Nakai et al. [6], Geng et al. [4] and Hou et al. [2]. In most studies, there is a correlation between both plotted quantities: higher microhardness means also higher Young's modulus. However, this is not the case in the present study: microhardness is the same for all alloys while the Young's modulus decreases to a value close to the lowest achieved values. The Young's modulus of Ti-26Nb-6Ta-7Zr- $0.7 \mathrm{O}$ is close to the value in the low-oxygen alloy with original $35 \mathrm{wt} \%$ of $\mathrm{Nb}$ but the microhardness is increased more than two times. 


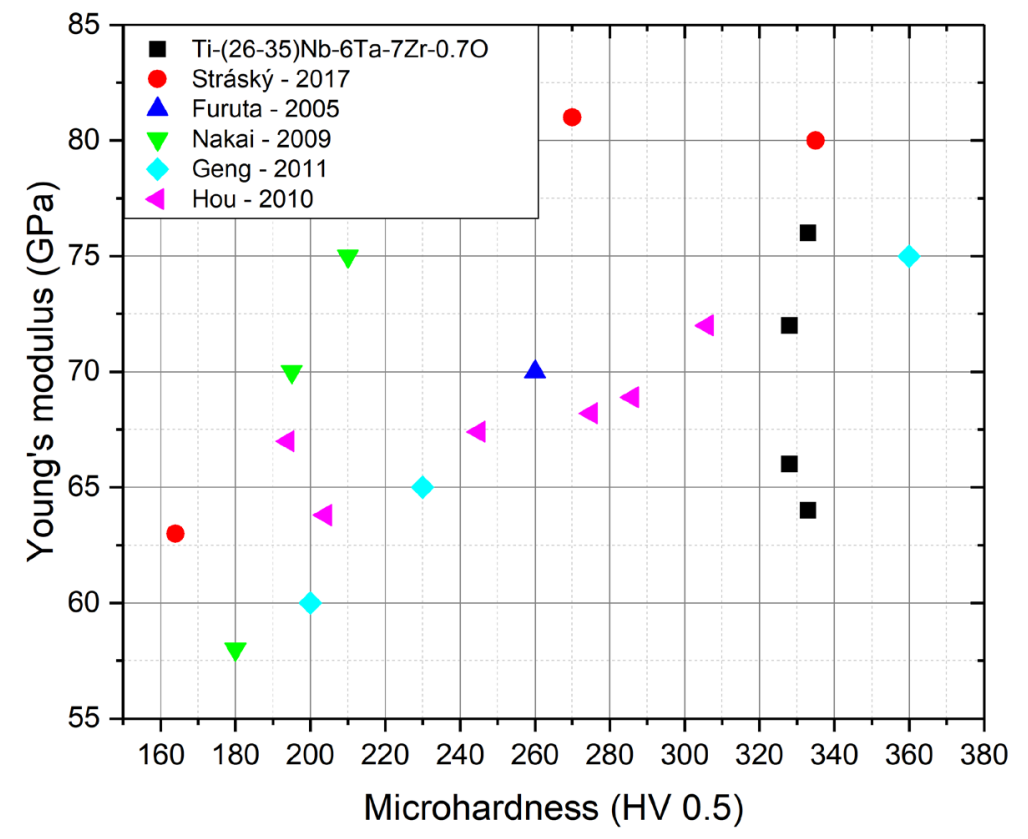

Fig. 3: Values of Young's modulus and microhardness of alloy from this study compared to [2-4,6,13]

We can argue, that further decrease of Young's modulus while retaining the same microhardness could be achieved by another decrease of $\mathrm{Nb}$ content leading to even lower e/a ratio. It is however unknown, whether the trends observed in our results would continue and thorough experiments must be conducted to find out the behavior at e/a values below 4.2.

\section{Conclusion}

Following conclusions can be drawn from the above stated results and discussion:

- 4 different Ti-Nb-Ta-Zr-O alloys were produced, containing high oxygen content of $0.7 \mathrm{wt} \%$ and various amounts of $\mathrm{Nb}$. All alloys contain pure beta phase after water quenching from $1000^{\circ} \mathrm{C}$.

- All alloys exhibit the same microhardness of aprox. $330 \mathrm{HV}$. Minor variations in the oxygen content do not play a significant role.

- Young's modulus decreases monotonously with the decrease of e/a ratio caused by lower Nb content. Value of $64 \mathrm{GPa}$ was measured in alloy Ti-26Nb-6Ta-7Zr-0.7O (wt.\%) with e/a ratio of 4.24.

- In comparison with other authors, the alloy Ti-26Nb-6Ta-7Zr-0.7O shows one of the lowest Young's moduli while having concurrently twice their microhardness.

\section{$\underline{\text { Acknowledgements }}$}

Grant Agency of the Czech Republic is acknowledged for financial support (project No. 17-20700Y). DP acknowledges Grant Agency of Charles University (project No. 1530217).

\section{$\underline{\text { References }}$}

[1] E. Eisenbarth, D. Velten, M. Müller, R. Thull, J. Breme, Biomaterials 25 (2004), 5705-5713.

[2] F. Q. Hou, S. J. Li, Y. L. Hao, R. Yang, Scripta Materialia 63 (2010), 54-57.

[3] T. Furuta, S. Kuramoto, J. Hwang, K. Nishino, T. Saito, Materials Transactions 46 (2005), 3001-3007.

[4] F. Geng, M. Niinomi, M. Nakai, Materials Science and Engineering: A 528 (2011), 5435-5445.

[5] Q. Wei, L. Wang, Y. Fu, J. Qin, W. Lu, D. Zhang, Materials \& Design 32 (2011), 2934-2939.

[6] M. Nakai, M. Niinomi, T. Akahori, H. Tsutsumi, M. Ogawa, Mater. Trans. 50 (2009), 2716-2720.

[7] M. Tane, T. Nakano, S. Kuramoto, M. Hara, M. Niinomi, N. Takesue, T. Yano, H. Nakajima, Acta Materialia 59 (2011), $6975-6988$.

[8] T. Furuta, S. Kuramoto, J. Hwang, K. Nishino, T. Saito, M. Niinomi, Materials Transactions 48 (2007), 1124-1130.

[9] M. Abdel-Hady, H. Fuwa, K. Hinoshita, H. Kimura, Y. Shinzato, M. Morinaga, Scripta Materialia 57 (2007), $1000-1003$. 
[10] P. K. Zysset, X. Edward Guo, C. Edward Hoffler, K. E. Moore, S. A. Goldstein, Journal of Biomechanics 32 (1999), $1005-1012$.

[11] J.-Y. Rho, T. Y. Tsui, G. M. Pharr, Biomaterials 18 (1997), 1325-1330.

[12] T. Ahmed, H. Rack, US Patent No. 5,871,595., 1999.

[13] J. Stráský, P. Harcuba, K. Václavová, K. Horváth, M. Landa, O. Srba, M. Janeček, Journal of the Mechanical Behavior of Biomedical Materials 71 (2017), 329-336.

[14] Y. L. Hao, S. J. Li, S. Y. Sun, C. Y. Zheng, R. Yang, Acta Biomaterialia 3 (2007), 277-286.

[15] J. I. Qazi, H. J. Rack, B. Marquardt, JOM 56 (2004), 49-51.

[16] J. Šmilauerová, M. Janeček, P. Harcuba, J. Stráský, J. Veselý, R. Kužel, H. J. Rack, Journal of Alloys and Compounds 724 (2017), 373-380. 